\title{
Decursin inhibits tumor progression in head and neck squamous cell carcinoma by downregulating $\mathrm{CXCR7}$ expression in vitro
}

\author{
MINA JOO ${ }^{1}$, JONG BEOM HEO ${ }^{2}$, SOLBI KIM ${ }^{1}$, NAYOUNG KIM ${ }^{1}$, HEUNG JIN JEON ${ }^{3}$, \\ YUEUN AN ${ }^{3}$, GYU-YONG SONG ${ }^{2}$, JIN-MAN KIM ${ }^{4}$ and HYO JIN LEE ${ }^{3,5}$ \\ ${ }^{1}$ Department of Medical Science, ${ }^{2}$ College of Pharmacy, Chungnam National University; \\ ${ }^{3}$ Infection Control Convergence Research Center, Departments of ${ }^{4}$ Pathology and ${ }^{5}$ Internal Medicine, \\ Chungnam National University College of Medicine, Daejeon 35015, Republic of Korea
}

Received August 18, 2021; Accepted December 6, 2021

DOI: $10.3892 / o r .2021 .8250$

\begin{abstract}
CXC chemokine receptor 7 (CXCR7) is frequently overexpressed in cancer and plays a significant role in tumor growth and metastasis. Consequently, inhibition of CXCR7 is important for treatment strategies. However, little is known concerning the biological role of CXCR7 and its underlying mechanisms in head and neck squamous cell carcinoma (HNSCC). The present study investigated the role of CXCR7 in HNSCC, as well as the effects of decursin, a pyranocoumarin compound isolated from Angelica gigas Nakai, on CXCR7 and its downstream signaling. Expression levels of CXCR7 in HNSCC cells were examined using flow cytometry, reverse transcriptase PCR, western blot analysis, and immunofluorescence. The effects of CXCR7 on cell proliferation, migration, and invasion were studied using CCK-8, gap closure, and transwell assays. The results revealed that decursin significantly reduced CXCR7 expression and inhibited cell proliferation, migration, and invasion of human HNSCC cell lines. In addition, decursin induced G0/G1 cell cycle arrest in CXCR7-overexpressing cells and decreased the levels of cyclin A, cyclin E, and CDK2. Furthermore, CXCR7 promoted cancer progression via the STAT3/c-Myc pathway in HNSCC; suppression of CXCR7 with decursin prevented this effect. These results suggest that $\mathrm{CXCR} 7$ promotes cancer progression through the STAT3/c-Myc pathway and that the
\end{abstract}

Correspondence to: Professor Hyo Jin Lee, Department of Internal Medicine, Chungnam National University College of Medicine, 282 Munhwa-ro, Jung-gu, Daejeon 35015, Republic of Korea E-mail: cymed@cnu.ac.kr

Professor Jin-Man Kim, Department of Pathology, Chungnam National University College of Medicine, 282 Munhwa-ro, Jung-gu, Daejeon 35015, Republic of Korea

E-mail: jinmank@cnu.ac.kr

Key words: CXC chemokine receptor 7, decursin, head and neck cancer, proliferation, migration, invasion, signal transducers and activators of transcription 3, c-Myc natural compound decursin targets $\mathrm{CXCR} 7$ and may be valuable in the treatment of HNSCC.

\section{Introduction}

Head and neck cancer represents the sixth most common malignancy worldwide, with approximately 500,000 new cases diagnosed each year; it remains one of the leading causes of cancer-related deaths (1). Head and neck squamous cell carcinoma (HNSCC) comprises the majority of head and neck cancers and represents a heterogeneous group of tumors that arise from the squamous epithelium of the oral cavity, oropharynx, larynx, and hypopharynx (2). HNSCC metastasizes to lymph nodes, resulting in poor prognosis (3). However, few oncogenes have been identified in HNSCC that can be exploited with targeted agents (4). Therefore, the identification of new biomarkers and drug targets is necessary for effective treatment of HNSCC. Many HNSCC patients present with locally advanced disease, often with prominent involvement of lymph nodes (2). Lymph node metastasis is affected by various factors in HNSCC. Recent studies have demonstrated that tumor cells express functionally active chemokine receptors and that expression of these receptors appears to regulate cellular functions associated with metastasis (5-7). The involvement of chemokines and their receptors in both normal and abnormal physiological behaviors, such as inflammation, immunity, chemotaxis, and metastasis of tumor cells, is under active investigation (8-10). CXC chemokine receptor type 7 (CXCR7) is an important marker of lymph node metastasis in HNSCC (11).

CXCR7 is a G-protein-coupled chemokine receptor; its ligands are CXCL12 and CXCL11. CXCR7 is upregulated in cancer cells and mediates a broad range of cellular activities, including proliferation, survival, and metastasis, by binding CXCL12 (12-14). Elevated levels of CXCR7 were found to be correlated with tumor aggressiveness and grade in various types of cancers, including non-small cell lung cancer (15), bladder cancer (16), breast cancer (17), and oral squamous cell carcinoma (18). In addition, CXCR7 expression is strongly associated with tumor size, lymph node metastasis, disease recurrence, and poor disease-specific survival, suggesting that CXCR7 expression results in more biologically aggressive 
tumors (19). Therefore, it will be important to study the role of CXCR7 in HNSCC cells to reveal potential relevant therapeutic targets to inhibit tumor progression.

Decursin, a pyranocoumarin compound isolated from the dried root of the Korean medicinal herb Angelica gigas Nakai, has been reported to exhibit antitumor activity in breast and gastric cancer (20-22). Pharmacological effects of this compound have also been reported, and include antibacterial and antileukemic activities, as well as antiangiogenic effects $(23,24)$. Decursin was found to inhibit tumor growth and to promote apoptosis in several cancer cell types, and exerts anticancer effects by inducing cell cycle arrest, particularly in prostate carcinomas (25). However, the relationship between decursin and its antitumor activity mediated by chemokine receptor signaling, especially CXCR7, is not fully understood in HNSCC. In the present study, the role of CXCR7 was investigated in HNSCC cells and whether decursin exerts antitumor activity by regulating CXCR7 and its downstream factors was further evaluated.

\section{Materials and methods}

Preparation of decursin and treatments. Decursin was synthesized using decursinol isolated from the dried roots of Korean angelica (A. gigas). Decusin was prepared by Professor Song's laboratory at the College of Pharmacy, Chungnam National University, Deajeon, as previously described (26). Briefly, in order to synthesize decursin, decursinol was dissolved in dry methylene chloride and cooled down in an ice bath. Dicyclohexylcarbodiimide, 3,3-dimethylacrylic acid, and 4-dimethylaminopyridine were then added with stirring. The reaction mixture was stirred at room temperature for $24 \mathrm{~h}$ and filtered. The filtrate was evaporated under reduced pressure and purified by flash column chromatography to obtain decursin as a white powder. The structure of decursin was confirmed by comparing nuclear magnetic resonance and mass spectrometry spectra. Decursin was dissolved in dimethyl sulfoxide (DMSO); in all experiments the concentration of DMSO was limited to $0.1 \%$. The dose of decursin 50 or $100 \mu \mathrm{M}$ was chosen based on previous studies $(27,28)$.

Cell culture and stable cell line establishment. The human HNSCC cell lines SNU1041 (KCBL No. 01041) and SNU1076 (KCBL No. 01076) were purchased from the Korean Cell Line Bank (Seoul, Korea). SNU1041 and SNU1076 cells were grown in RPMI medium (Welgene) supplemented with $10 \%$ fetal bovine serum (FBS) and $1 \mathrm{X}$ penicillin/streptomycin. Cells were cultured at $37^{\circ} \mathrm{C}$ under $5 \% \mathrm{CO}_{2}$ and $95 \%$ relative humidity. CXCR7 overexpression in HNSCC cell lines was conducted as previously described (22). Overexpression of CXCR7 in HNSCC cells was produced by lentivirus-mediated transduction of full-length human CXCR7 sub-cloned into a pLVX-EF1 $\alpha$-IRES-Puro lentiviral vector (Clontech Laboratories, Inc.) and mock transfected as a negative control. To generate stable transfectants, the acquired lentiviral vector was co-transfected into 293T cells with virus packaging mix (Sigma Aldrich; Merck KGaA) using Lipofectamine 3000 (Invitrogen; Thermo Fisher Scientific, Inc.) according to the manufacturer's instructions. The virus was harvested from the supernatant and concentrated with lenti-X-concentrator
(Clontech Laboratories, Inc.), and then added to SNU1041 and SNU1076 cells along with $5 \mu \mathrm{g} / \mathrm{ml}$ polybrene (Santa Cruz Biotechnology, Inc.). Puromycin-resistant cells were selected by culture for 2 weeks in the presence of puromycin. CXCR7 expression levels were analyzed by flow cytometry (Beckman Coulter), reverse transcriptase PCR (RT-PCR), and western blot analysis.

Reagents and antibodies. Antibodies against CXCR7 (dilution 1:1,000, cat. no. ab38089; Abcam), GAPDH (dilution 1:2,000, cat. no. sc-25308; Santa Cruz Biotechnology, Inc.), cyclin A (dilution 1:1,000, cat. no. 4565; Cell Signaling Technology, Inc.), cyclin E (dilution 1:1,000, cat. no. 4129; Cell Signaling Technology, Inc.), CDK2 (dilution 1:1,000, cat. no. 2546; Cell Signaling Technology, Inc.), phosphorylated-STAT3 (p-STAT3; dilution 1:1,000, cat. no. 9134; Cell Signaling Technology, Inc.), STAT3 (dilution 1:1,000, cat. no. 9132; Cell Signaling Technology, Inc.), c-MYC (dilution 1:1,000, cat. no. sc-40; Santa Cruz Biotechnology, Inc.) were used in the western blot analysis and immunofluorescence. Interleukin 6 (IL-6; cat. no. 200-06; Peprotech, Inc.) and stromal cell-derived factor $1 \alpha$ (SDF-1 $\alpha$ or CXCL12; cat. no. 300-28A; Peprotech, Inc.) were resuspended in medium and used to treat the cells.

Small interfering RNA (siRNA) treatment and transfection. We obtained CXCR7 siRNA antisense (5'-CGCUCUCCU UCAUUUACA-3'), sense (5'-UGUAAAUGAAGGAGA GCG-3') (Bioneer Corp.), and non-targeting control siRNA (cat. no. sc-37007; Santa Cruz Biotechnology, Inc.). Cells were transfected using Lipofectamine RNAi MAX (Invitrogen; Thermo Fisher Scientific, Inc.).

Reverse transcriptase (RT)-PCR analysis. Total RNA was isolated using TRIzol reagent (Thermo Fisher Scientific, Inc.) according to the manufacturer's instructions. First-strand cDNA was prepared from an RNA template $(2 \mu \mathrm{g})$ using the cDNA qPCR RT Master Mix (Toyobo Life Science). RT-RCR was performed using the EmeraldAmp Master Mix (Takara Bio). The PCR program included 40 cycles of $95^{\circ} \mathrm{C}$ for $15 \mathrm{sec}, 60^{\circ} \mathrm{C}$ for $1 \mathrm{~min}$, and $72^{\circ} \mathrm{C}$ for $1 \mathrm{~min}$. The primers and oligonucleotide sequences are described in Table SI. The gel was visualized and analyzed under the GelDoc Xr system (Bio-Rad Laboratories) where band sizing and molecular weight were determined by Image Lab analysis software version 4.1 (Bio-Rad Laboratories) in relation to $100 \mathrm{bp}$ DNA ladder (Bioneer).

Flow cytometry. Surface expression of CXCR7 was evaluated by flow cytometry. Cells were harvested with phosphate-buffered saline (PBS) containing $0.1 \%$ bovine serum albumin (BSA). After cells were incubated with $10 \mu \mathrm{l}$ of conjugated PE-CXCR7 (R\&D Systems) or mouse PE-IgG2A antibodies (negative control) by shaking for $1 \mathrm{~h}$ at room temperature. Next, after washing three times with PBS containing $0.1 \%$ BSA, expression levels were measured using flow cytometry (Beckman Coulter) and the Kaluza analysis program (version 1.2; Beckman Coulter).

Western blot analysis. Western blot analysis was performed as previously described (11). Briefly, cells were washed in PBS 
and lysed in ProEX ${ }^{\mathrm{TM}}$ CETi Lysis buffer (Translab) containing a protease inhibitor cocktail. Cell lysates were separated using sodium dodecyl sulfate polyacrylamide gel electrophoresis (SDS-PAGE) and transferred to polyvinylidene fluoride membranes (EMD Millipore). Membranes were blocked with the ProNA ${ }^{\mathrm{TM}}$ General-block solution (TLP-115.1P; Translab) for $1 \mathrm{~h}$ and incubated with the indicated primary antibodies at $4^{\circ} \mathrm{C}$ for overnight. After membranes had been washed, they were incubated with the corresponding horseradish peroxidase-conjugated anti-rabbit IgG (dilution 1:5,000, cat. no. 7074; Cell Signaling Technology, Inc.) and anti-mouse IgG (dilution 1:5,000, cat. no. 7076; Cell Signaling Technology, Inc.) antibodies diluted in blocking solution. The immunoreactive polypeptides were detected using an enhanced chemiluminescence substrate (Thermo Fisher Scientific, Inc.).

In vitro cell proliferation assay. Medium containing 50 or $100 \mu \mathrm{M}$ decursin was added to cells in a 96-well plate. Cell proliferation was measured using the Cell Counting Kit-8 (CCK-8; Dojindo Molecular Technologies). Cell proliferation was determined every $24 \mathrm{~h}$ for 4 days and absorbance was measured at $450 \mathrm{~nm}$ (Molecular Devices). For the anchorage-dependent growth assay, cells were seeded in 6 -well plates. After cell attachment, 50 or $100 \mu \mathrm{M}$ decursin was added to the wells for $48 \mathrm{~h}$. The cells were then cultured with fresh medium for 2 weeks. The colonies were fixed in $10 \%$ formalin and stained with $0.1 \%$ crystal violet (Sigma Aldrich; Merck KGaA) at room temperature for $1 \mathrm{~h}$. After stained cells were dissolved in $70 \%$ ethanol, absorbance at $595 \mathrm{~nm}$ was measured using a spectrophotometer.

Gap closure assay. A total of $5 \times 10^{4}$ cells were seeded on each side of the chamber (Ibidi, cat. no. 81176; Gräfelfing) with culture inserts for live-cell analysis. After growth for $24 \mathrm{~h}$, the chamber inserts were removed, and the two cell islands were washed with PBS to remove debris and maintained in serum-free medium with different concentrations of 50 or $100 \mu \mathrm{M}$ decursin. Cells were observed at regular intervals and imaged using phase contrast microscopy.

Migration and invasion assays. The migration and invasion assay were performed using 8- $\mu \mathrm{m}$-pore transwell chambers (cat. no. 353097; Corning, Inc.). The lower chamber was coated with $0.1 \%$ gelatin (Sigma Aldrich; Merck KGaA) for migration, and the upper chamber was coated with $25 \mu \mathrm{g} / \mathrm{ml}$ Matrigel for the invasion assay (BD Biosciences). Serum-free medium containing 50 or $100 \mu \mathrm{M}$ decursin was added to the upper chamber and $1 \times 10^{5}$ cells were seeded in each well. Culture medium containing $10 \%$ serum was added to the lower chamber and the chamber was incubated at $37^{\circ} \mathrm{C}$ for $24 \mathrm{~h}$ (migration) or $48 \mathrm{~h}$ (invasion). After the chambers were removed from the upper surface of the transwell membrane with a cotton swab, cells were fixed with $10 \%$ formalin and stained with $0.1 \%$ crystal violet. The number of cells passing through the chamber was counted under a microscope (Olympus IX71). Five randomly chosen fields were counted for each assay.

Immunofluorescence staining. Cells were seeded in an 8-well chamber slide (Nunc ${ }^{\mathrm{TM}}$ Lab-Tek $\mathrm{II}^{\mathrm{TM}}$; Thermo Fisher Scientific, Inc.) at a concentration of $1 \times 10^{3}$ cells and treated with $100 \mu \mathrm{M}$ decursin. After incubation, the cells were fixed with $10 \%$ formalin for $20 \mathrm{~min}$ at room temperature and then washed with PBS. Cell membranes were permeabilized with 0.3\% Triton X-100 (Sigma Aldrich; Merck KGaA) for 20 min and maintained in blocking buffer (4\% BSA in PBS) for $1 \mathrm{~h}$ at room temperature. After blocking, the 8-well chamber slide was reacted with anti-CXCR7 (Abcam) antibody overnight at $4^{\circ} \mathrm{C}$. The slides were washed with PBS and incubated with Alexa 488-conjugated secondary antibodies (cat. no. A11001; Invitrogen; Thermo Fisher Scientific, Inc.) in PBS for $1 \mathrm{~h}$ at room temperature. For analysis of the actin cytoskeleton, cells were stained with rhodamine-conjugated phalloidin (Sigma Aldrich; Merck KGaA) diluted in PBS for $40 \mathrm{~min}$ at room temperature followed by three washes in PBS. Nuclei were counterstained with DAPI (Vector Laboratories).

Cell cycle analysis. For cell cycle analysis through propidium iodide (PI) staining, $1 \times 10^{5}$ cells were seeded in 6 -well plate and treated with 50 or $100 \mu \mathrm{M}$ decursin or siRNA for $48 \mathrm{~h}$. Afterwards, the cells were fixed in $70 \%$ ice-cold ethanol overnight at $-20^{\circ} \mathrm{C}$ and incubated with FxCycle ${ }^{\mathrm{TM}} \mathrm{PI} / \mathrm{RNase}$ Staining Solution (cat. no. F10797; Invitrogen; Thermo Fisher Scientific, Inc.) for $30 \mathrm{~min}$ at room temperature. Fluorescence was analyzed using flow cytometry (Beckman Coulter) and the Kaluza analysis program (version 1.2; Beckman Coulter).

GEPIA Database. The Gene Expression Profiling Interactive Analysis (GEPIA) database (http://gepia.cancer-pku.cn/), a newly developed web-based tool, provides key interactive and customizable functions including tumor vs. normal differential expression analysis, profiling plotting in accordance with cancer types or different pathological stages, correlation analysis, patient survival analysis, similar gene detection, and dimensionality reduction analysis based on the Cancer Genome Atlas (TCGA) and the genotype-tissue expression data (29). P-values are represented by asterisks in the GEPIA results.

Statistical analysis. Each experimental condition was performed in triplicate to evaluate the mean \pm standard deviation (SD). All statistical analysis of the data was performed using Prism (GraphPad Software, v 5.01; GraphPad Software, Inc.). To determine the difference between two groups, the unpaired two-tailed Student's t-test was applied. One-way ANOVA followed by Dunnett's test was applied to compare multiple data. In all cases, the minimum statistical significance was set at $\mathrm{P}<0.05$.

\section{Results}

CXCR7 promotes proliferation, migration, and invasion of HNSCC cells. To investigate how CXCR7 regulates tumor progression in HNSCC, we established stable cell lines overexpressing CXCR7 (SNU1041-CXCR7 and SNU1076-CXCR7) using lentivirus-mediated transduction of an expression vector for full-length human CXCR7. Overexpression of CXCR7 was confirmed in the HNSCC SNU1041 and SNU1076 cell lines using flow cytometry, RT-PCR, western blot analysis, and immunofluorescence (Fig. 1A and B and S1A). Overexpression of CXCR7 significantly increased the proliferation of the 
A

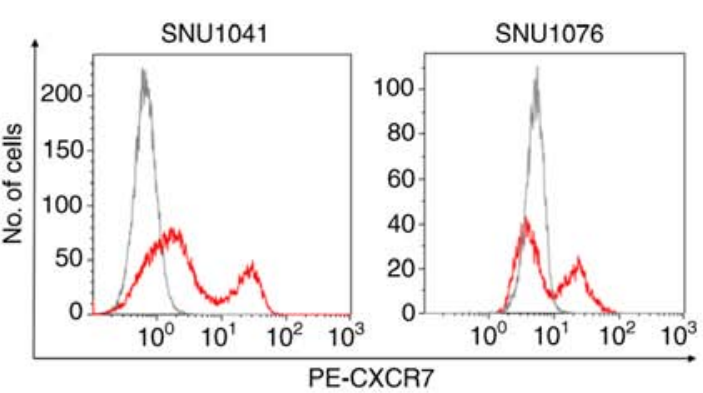

C

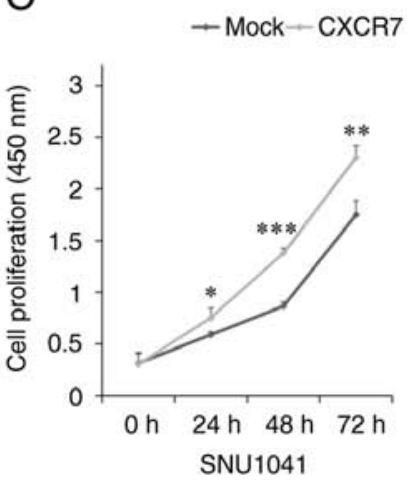

$E$

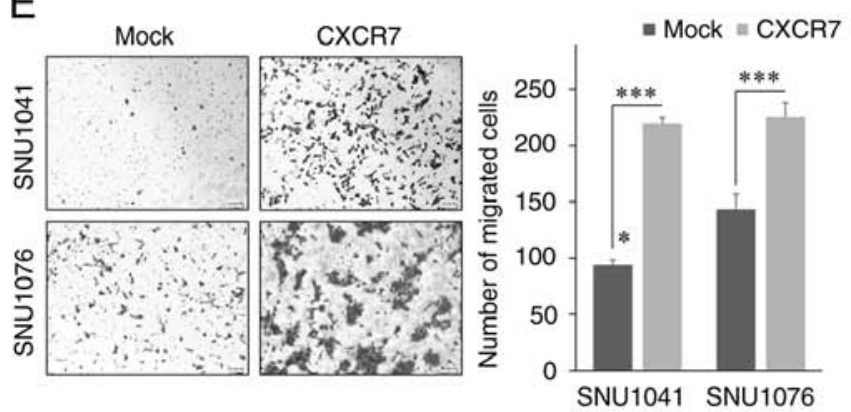

B

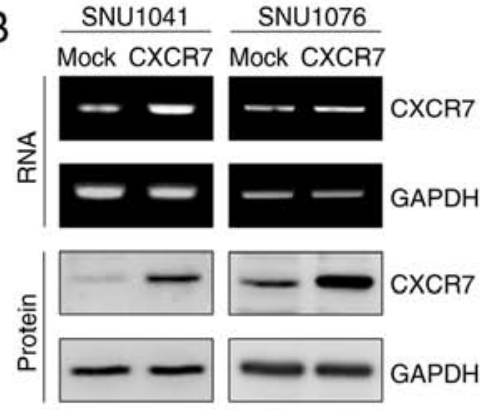

D

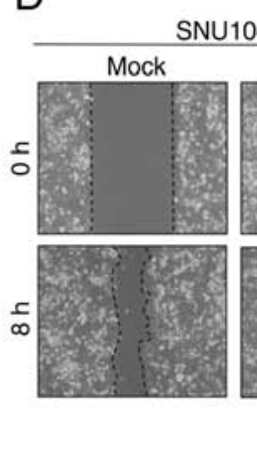

SNU1041
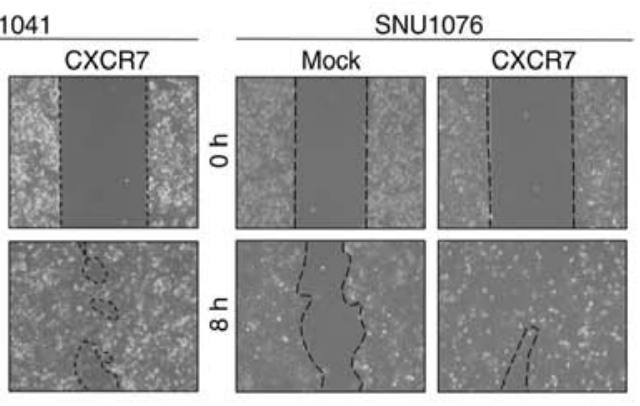

$\mathrm{F}$
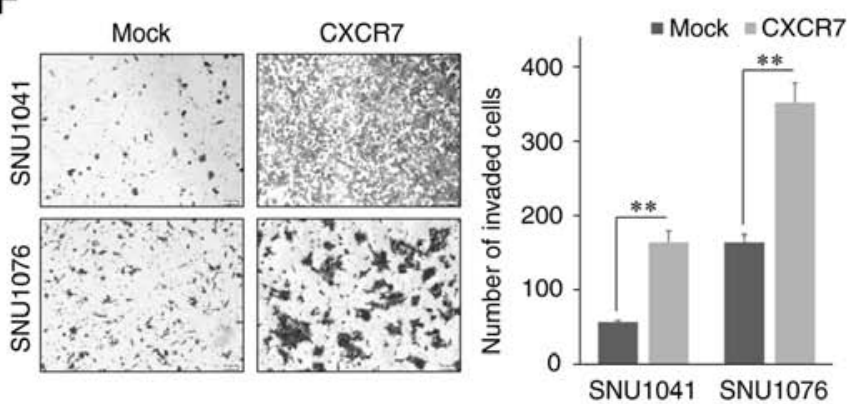

Figure 1. CXCR7 increases cell proliferation, migration, and invasion. (A) Relative expression of CXCR7 in two different HNSCC cell lines, SNU1041 and SNU1076. The surface expression of CXCR7 was evaluated by flow cytometry using a phycoerythrin (PE)-anti-CXCR7 monoclonal antibody to detect CXCR7 expression; a matched PE mouse IgG served as the isotype control. (B) RT-PCR and western blot analysis showing increased expression of CXCR7 in CXCR7-overexpressing cells compared with mock cells. Blots are representative of 3 independent experiments. Histograms of the RNA and protein expression levels are presented in Fig. S5A. (C) Cell proliferation rate by the cell counting assay in CXCR7-overexpressing and mock cells. Three independent experiments were carried out in triplicate. (D) Gap closure assay indicating that CXCR7 overexpression enhanced cell motility. Three independent experiments were carried out in triplicate. (E) Migration and (F) invasion assays showing that CXCR7 overexpression promoted cell migration and invasion. Three independent experiments were carried out in triplicate. ${ }^{*} \mathrm{P}<0.05,{ }^{* *} \mathrm{P}<0.01$, and ${ }^{* * *} \mathrm{P}<0.001$. HNSCC, head and neck squamous cell carcinoma; $\mathrm{CXCR} 7$, CXC chemokine receptor type 7 .

HNSCC cell lines (Fig. 1C). CXCR7 overexpression also significantly increased cell motility in a gap closure assay. CXCR7-overexpressing cells nearly closed the wide gaps when compared to the mock cells (Fig. 1D). In addition, CXCR7-overexpressing cells showed significantly increased migration and invasion compared with the mock cells (Fig. 1E and F). Furthermore, SDF-1 $\alpha$ treatment increased the cell migration and invasion of the CXCR7-overexpressed HNSCC cells (Fig. S1B). These findings indicate that CXCR7 promotes proliferation, migration, and invasion of HNSCC cells.

Decursin reduces expression of CXCR7 and inhibits proliferation of HNSCC cells. To confirm the effect of decursin on CXCR7, changes in CXCR7 expression in decursin-treated HNSCC cells were investigated. Flow cytometry, western blot analysis, and immunofluorescence confirmed that decursin treatment decreased expression of CXCR7 in a dose-dependent manner (Fig. 2A-C). Next, decursin treatment inhibited proliferation of CXCR7-overexpressing cells in a dose-dependent manner (Fig. 2D). Decursin-mediated inhibition of proliferation was dose dependent in bright field imaging (Fig. S2). In addition, decursin suppressed cell growth in a dose-dependent manner, as determined by the number of colonies in an anchorage-dependent growth assay (Fig. 2E). These results suggest that decursin reduces cell proliferation via downregulation of CXCR7.

Decursin induces G0/G1 cell cycle arrest by downregulating CXCR7 expression. To determine whether decursin-mediated inhibition of proliferation was associated with the cell cycle, the effects of decursin on the cell cycle distribution of CXCR7-overexpressing cells were confirmed. Treatment with 
A

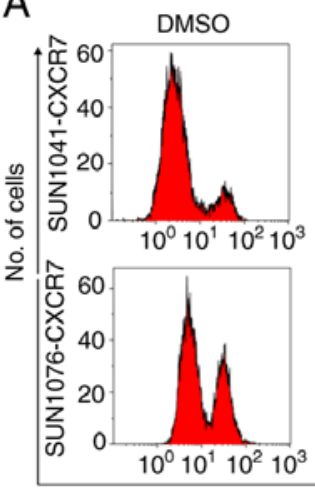

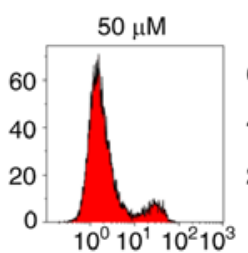

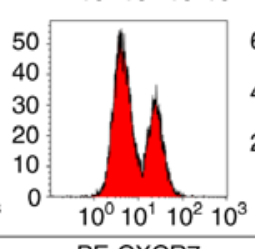
PE-CXCR7

C
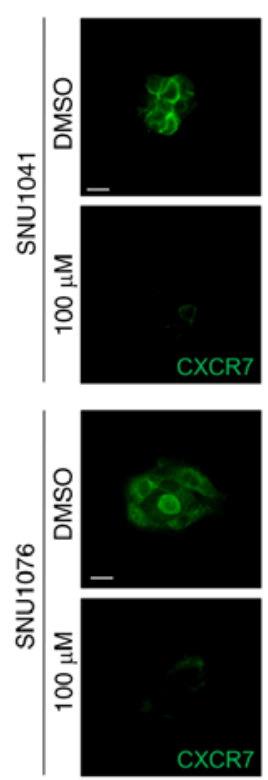
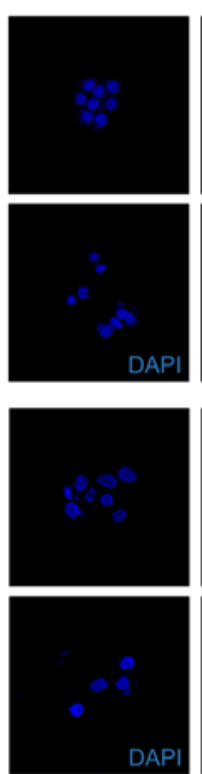

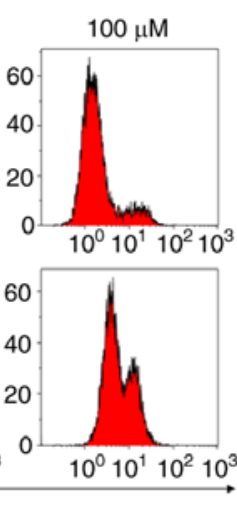

D

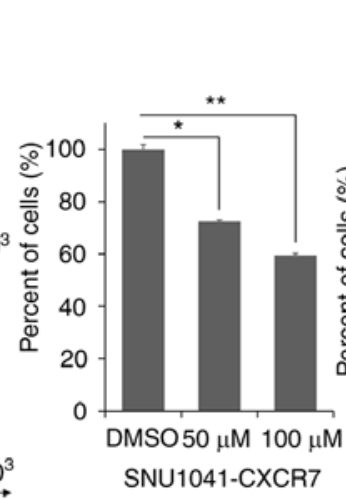

$\begin{aligned} & \text { Decursin } \\ & \rightarrow \text { DMSO }\end{aligned}-50 \mu \mathrm{M} \rightarrow-100 \mu \mathrm{M}$

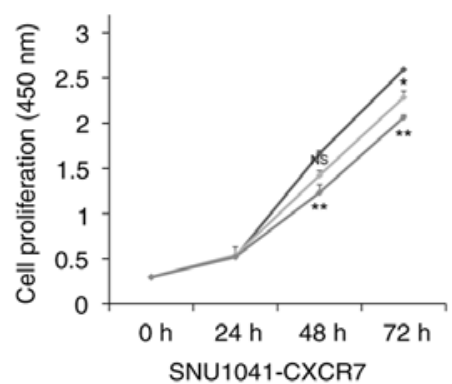

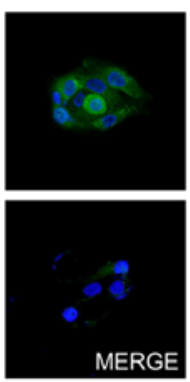
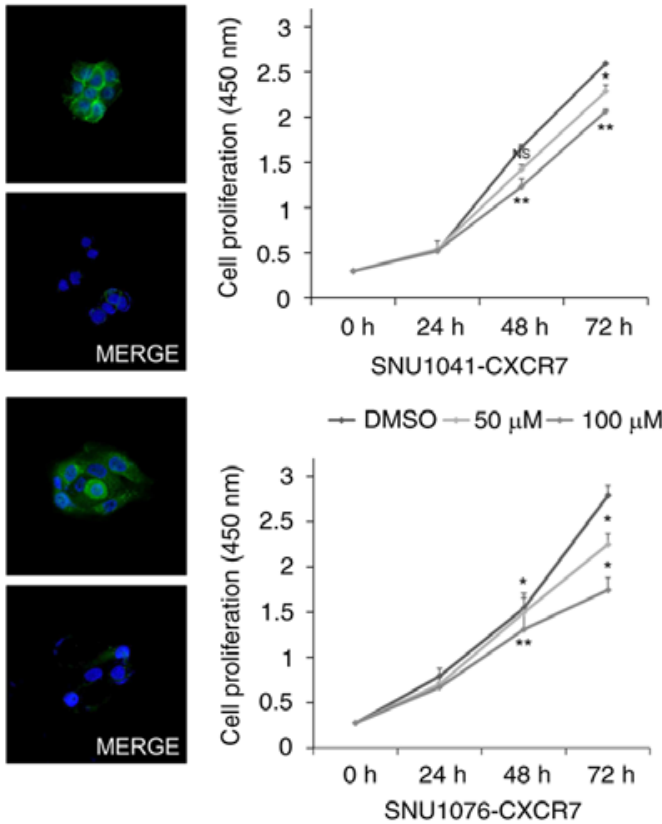

B

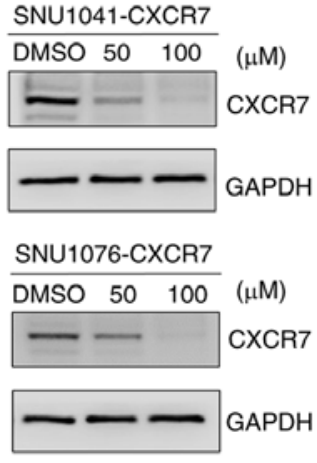

E
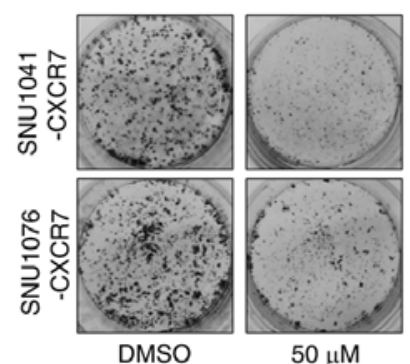

$50 \mu \mathrm{M}$
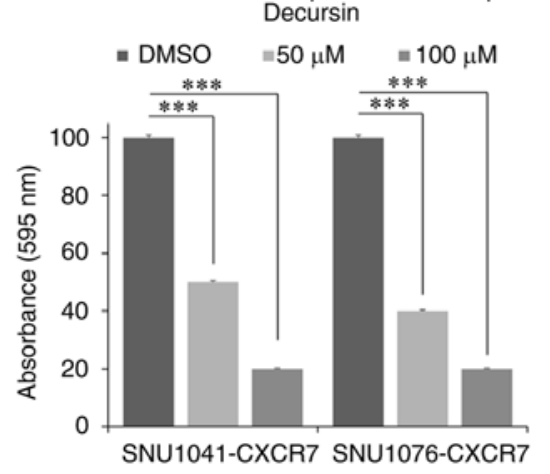

Figure 2. Decursin reduces CXCR7 expression and cell proliferation. (A and B) Expression of CXCR7 in SNU1041-CXCR7 and SNU1076-CXCR7 HNSCC cells treated with 50 or $100 \mu \mathrm{M}$ decursin for $48 \mathrm{~h}$ by flow cytometry and western blot analysis. Three independent experiments were carried out in triplicate. Blots are representative of 3 independent experiments. Histograms of the protein expression levels are presented in Fig. S5B. (C) Representative immunofluorescence images of CXCR7 in cells treated with $100 \mu \mathrm{M}$ decursin for $48 \mathrm{~h}$. Scale bar, $100 \mu \mathrm{m}$. (D) Cells were seeded in 96-well plates and treated with 50 or $100 \mu \mathrm{M}$ decursin for 24,48 , and $72 \mathrm{~h}$. Following treatment with decursin, cell viability was measured with the CCK-8 assay. Three independent experiments were carried out in triplicate. (E) Decursin suppressed cell growth, as determined by an anchorage-dependent growth assay. SNU1041-CXCR7 and SNU1076-CXCR7 cells were treated with 50 or $100 \mu \mathrm{M}$ decursin for $48 \mathrm{~h}$. Three independent experiments were carried out in triplicate. Magnification, $\mathrm{x} 200$. NS, not significant. ${ }^{*} \mathrm{P}<0.05,{ }^{* *} \mathrm{P}<0.01$, and ${ }^{* * * *} \mathrm{P}<0.001$. HNSCC, head and neck squamous cell carcinoma; CXCR7, CXC chemokine receptor type 7.

decursin significantly increased the percentage of cells in the G0/G1 phase in a dose-dependent manner compared with the control, whereas the percentage of cells in the $S$ phase and $\mathrm{G} 2 / \mathrm{M}$ phase was decreased in both CXCR7-overexpressing cell lines (Fig. 3A). In addition, cell cycle regulatory proteins cyclin A, cyclin E, and CDK2 were downregulated in a dose-dependent manner following treatment with decursin in the CXCR7-overexpressing cells (Fig. 3B and S3A). To confirm whether decursin-induced cell cycle arrest was due to a decrease in CXCR7, we knocked down CXCR7 expression using siRNA in CXCR7-overexpressing cells (Fig. S3B). Knockdown of CXCR7 significantly increased the proportion of cells in the G0/G1 phase compared with the control, whereas it decreased the proportion of cells in the $\mathrm{S}$ phase and G2/M phase (Fig. 3C). Knockdown of CXCR7 decreased cyclin A, cyclin E, and CDK2 expression (Fig. 3D). In addition, knockdown of CXCR7 also suppressed cell migration and invasion of CXCR7-overexpressing cells (Fig. S3C). These results demonstrated that decursin induced cell cycle arrest in G0/G1 phase and inhibited cell motility and invasiveness by downregulating CXCR7 expression.

Decursin suppresses cell motility, migration, and invasion in HNSCC cells. To determine the effect of decursin on motility and invasiveness, cell motility was assessed using the gap closure and transwell assays. Decursin significantly impaired the motility of CXCR7-overexpressing cells (Fig. 4A). In addition, cell migration and invasion were significantly 
A
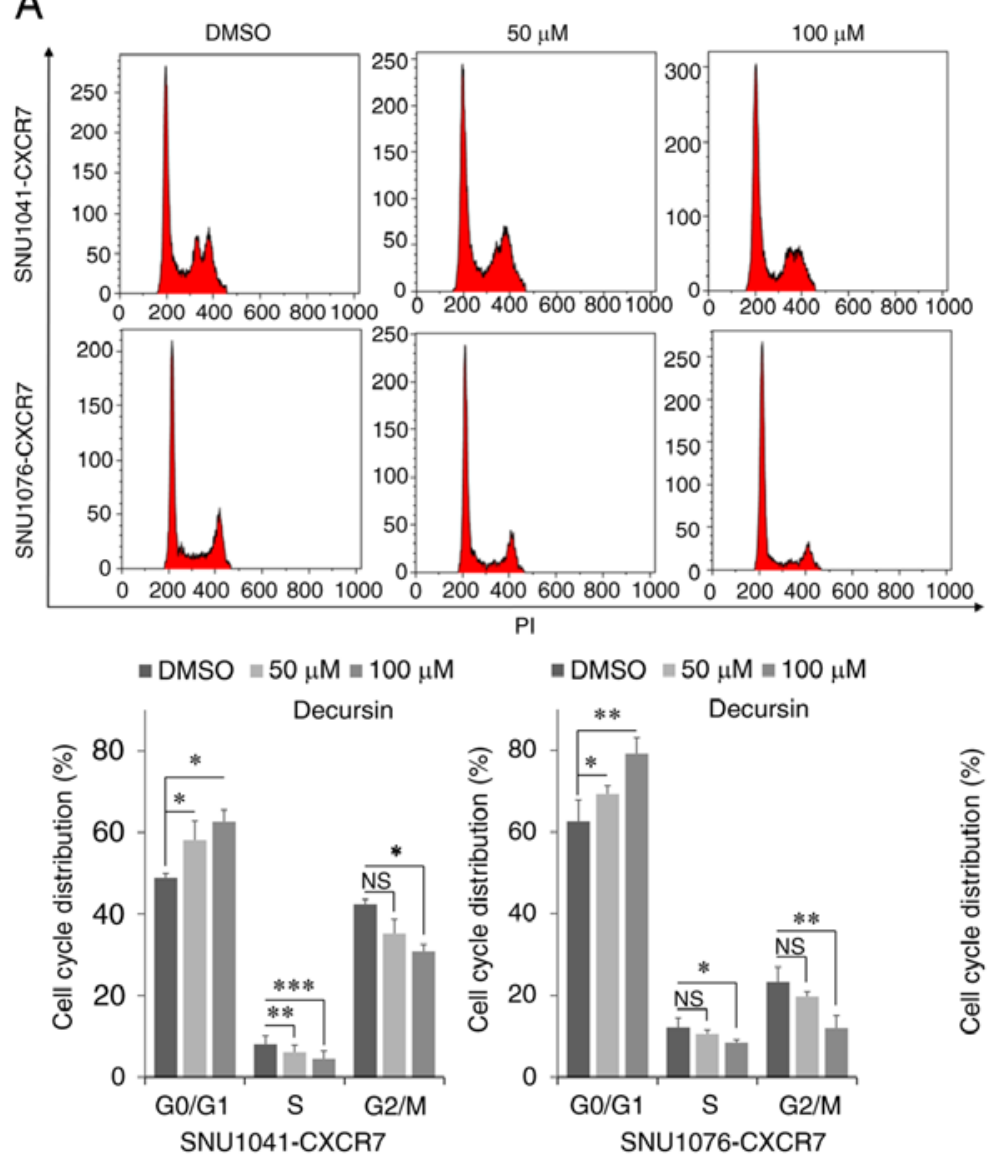

B

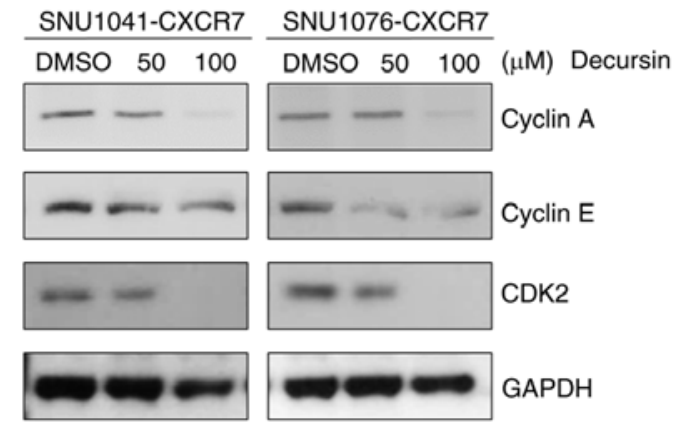

C
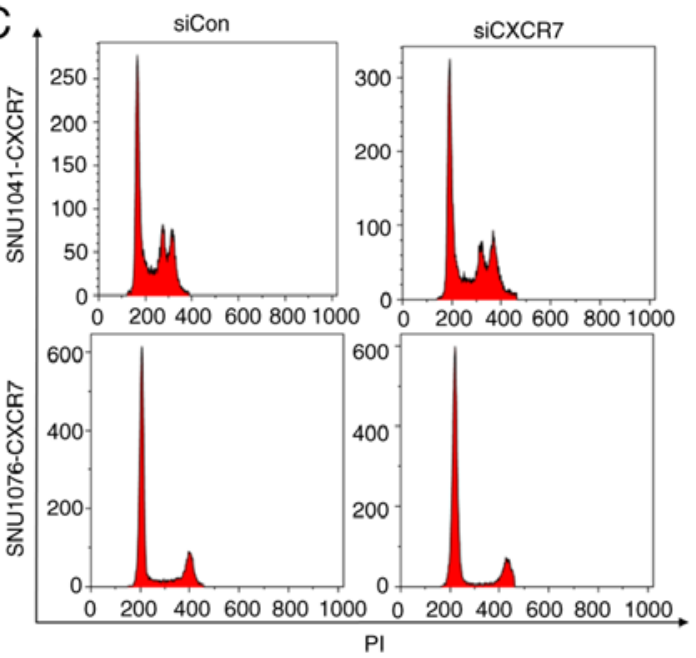

m siCon $=\operatorname{siCXCR7}$

= siCon $=\operatorname{siCXCR7}$
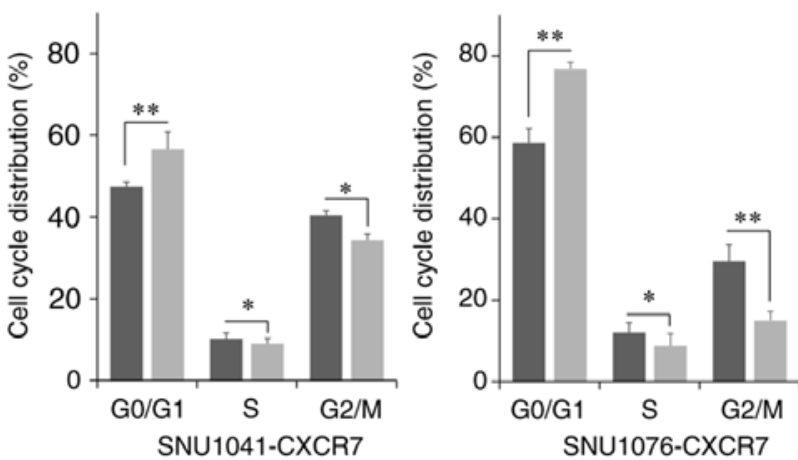

SNU1041-CXCR7 SNU1076-CXCR7

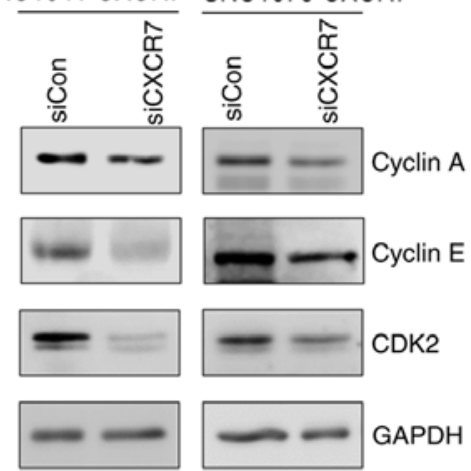

Figure 3. Decursin induces cell cycle arrest in the G0/G1 phase. (A) Cell cycle analysis by flow cytometry of SNU1041-CXCR7 and SNU1076-CXCR7 HNSCC cells treated with 50 or $100 \mu \mathrm{M}$ decursin after propidium iodide (PI) staining. The percentage of cells in G0/G1, S and G2/M phases are annotated in each column. Three independent experiments were carried out in triplicate. (B) Western blot analysis of cell cycle-related proteins. Blots are representative of 3 independent experiments. Histograms of the protein expression levels are presented in Fig. S5C. (C) Cell cycle analysis by flow cytometry after $48 \mathrm{~h}$ of siCXCR7 transfection in SNU1041-CXCR7 and SNU1076-CXCR7 cells after PI staining. The percentage of cells in the G0/G1, S and G2/M phases are annotated in each column. Three independent experiments were carried out in triplicate. (D) Western blot analysis of cell cycle-related proteins after knockdown of CXCR7. Blots are representative of 3 independent experiments. Histograms of the protein expression levels are presented in Fig. S5D. NS, not significant. ${ }^{*} \mathrm{P}<0.05,{ }^{* *} \mathrm{P}<0.01$, and ${ }^{* * *} \mathrm{P}<0.001$. HNSCC, head and neck squamous cell carcinoma; CXCR7, CXC chemokine receptor type 7.

reduced in CXCR7-overexpressing cells treated with decursin (Fig. 4B and C). Using phalloidin staining, it was observed that stress fiber formation was suppressed in decursin-treated cells (Fig. 4D). Taken together, these findings indicate that decursin inhibits the motility, migration, and invasion of CXCR7-overexpressing cells.

Decursin downregulates c-MYC expression by inhibiting CXCR7-mediated STAT3 signaling. Next, the mechanism by which decursin inhibits the proliferation, migration, and invasion of HNSCC cells was investigated. We screened several signaling pathways and found that overexpression of CXCR7 increased STAT3 phosphorylation (p-STAT3) in both CXCR7-overexpressing cell lines (Fig. S4A and Table SII). Furthermore, the GEPIA dataset showed increased expression of CXCR7 and STAT3 in HNSCC tissues (Fig. S4B). There was a correlation between CXCR7 and STAT3 expression (Fig. S4C). Overexpression of CXCR7 
A

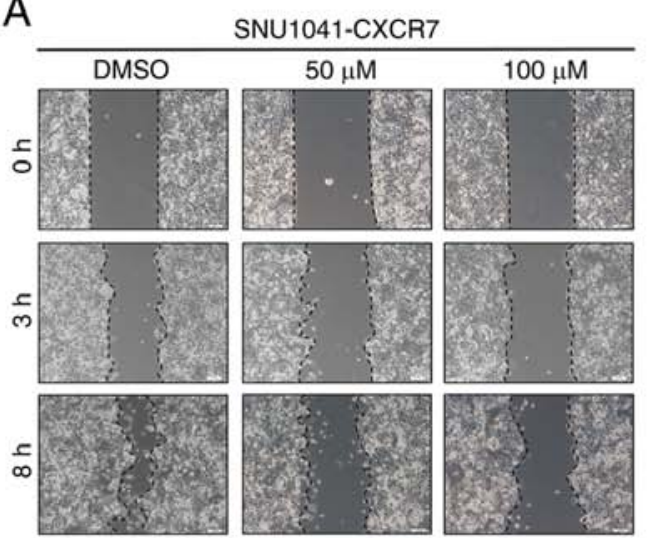
SNU1076-CXCR7
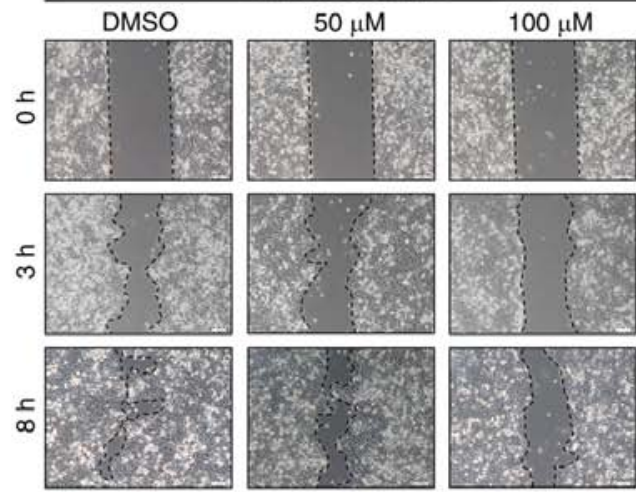

B
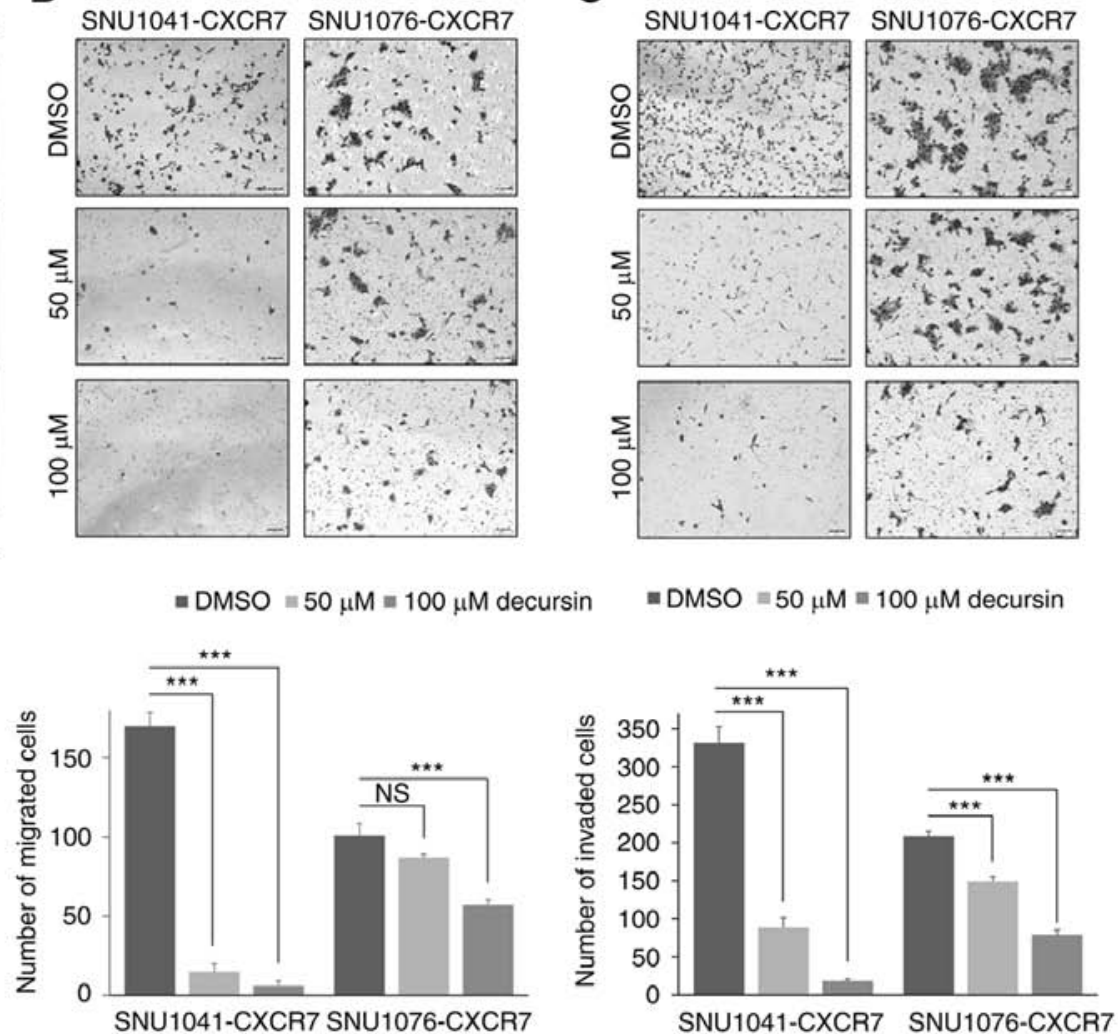

D
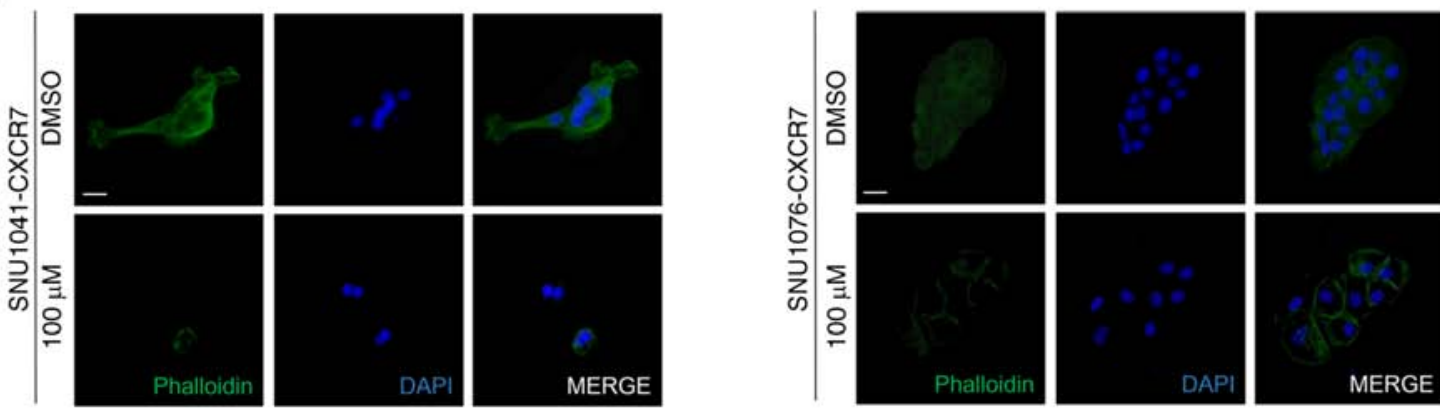

Figure 4. Decursin reduces motility, migration, and invasion of HNSCC cells. (A) Gap closure assay in SNU1041-CXCR7 and SNU1076-CXCR7 cells treated with 50 or $100 \mu \mathrm{M}$ decursin for $48 \mathrm{~h}$. Three independent experiments were carried out in triplicate. Transwell migration (B) and invasion (C) assays. Cells were pre-incubated with 50 or $100 \mu \mathrm{M}$ decursin. Three independent experiments were carried out in triplicate. (D) Representative immunofluorescence images of phalloidin staining of actin stress fibers in cells treated with $100 \mu \mathrm{M}$ decursin. Scale bar, $100 \mu \mathrm{m}$. NS, not significant. ${ }^{* * *} \mathrm{P}<0.001$. HNSCC, head and neck squamous cell carcinoma; CXCR7, CXC chemokine receptor type 7.

also increased c-MYC and p-STAT3 (Fig. 5A). In addition, STAT3 phosphorylation and c-MYC expression were decreased following knockdown of CXCR7 in the CXCR7-overexpressing cells (Fig. 5B); STAT3 phosphorylation and c-MYC expression were also reduced in the decursin-treated CXCR7-overexpressing cells (Fig. 5C). Following treatment of CXCR7-overexpressing cells with IL-6, a growth factor and inducer of STAT3 phosphorylation, STAT3 phosphorylation and c-MYC expression were increased, whereas decursin markedly inhibited p-STAT3, c-MYC, and CXCR7 expression. Decursin in combination with IL-6 reduced p-STAT3 and c-MYC to a lesser degree than treatment with decursin alone (Fig. 5D). These results demonstrate that decursin suppresses the CXCR7/STAT3/ c-MYC signaling axis and decursin exhibits anticancer activity in HNSCC (Fig. 5E).

\section{Discussion}

The development of effective target therapies for head and neck squamous cell carcinoma (HNSCC) requires in-depth knowledge of the underlying mechanisms of the complex signaling networks related to cancer development and progression. In the present study, it was demonstrated that decursin, a pyranocoumarin compound isolated from Angelica gigas Nakai, exhibited anticancer activity in HNSCC by downregulating the CXCR7/STAT3/c-MYC signaling pathway and inducing G0/G1 cell cycle arrest. Moreover, it was shown that decursin inhibited cell motility, migration, and invasion in vitro. Our findings showed that $\mathrm{CXCR} 7$ promotes cancer progression in HNSCC through the STAT3/c-MYC pathway and that decursin may be a useful treatment by which to target CXCR7 in HNSCC. 
A

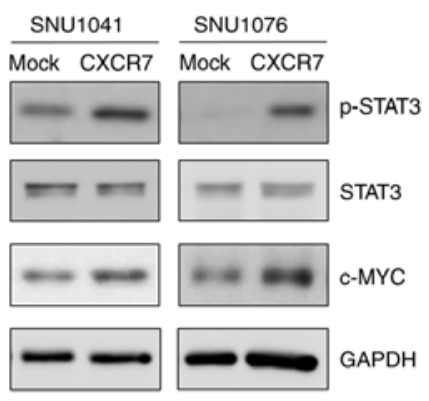

B

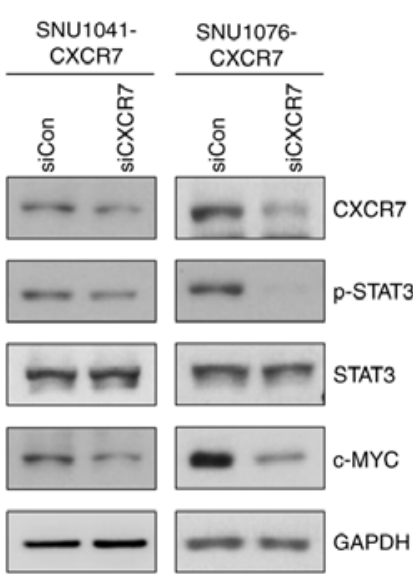

C

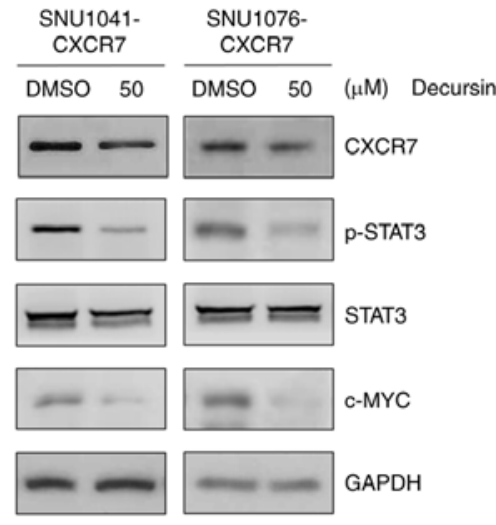

D

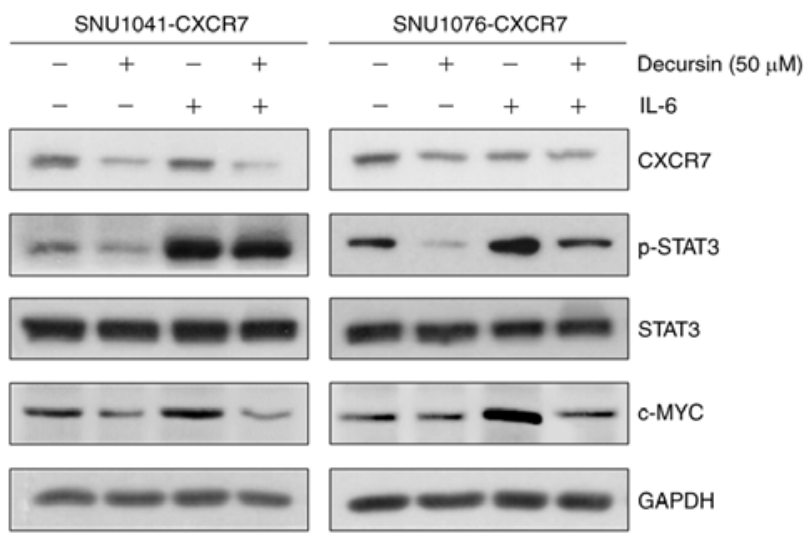

E

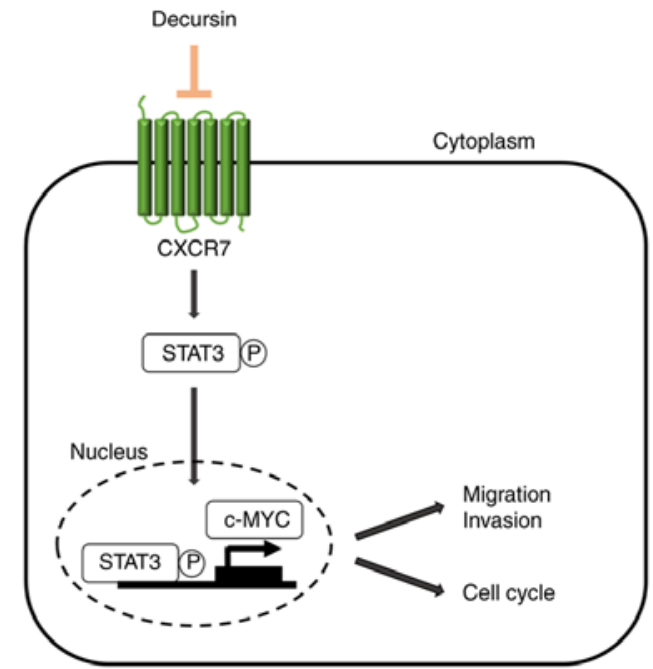

Figure 5. Decursin downregulates c-MYC expression by inhibiting CXCR7-mediated STAT3 signaling. (A) Western blot analysis of phospho-STAT3 and c-MYC following CXCR7 overexpression. Histograms of the protein expression levels are presented in Fig. S5E. (B) Western blot analysis of phosphorylated (p)-STAT3 and c-MYC following knockdown of CXCR7. Histograms of the protein expression levels are presented in Fig. S5F. (C) Treatment with $50 \mu \mathrm{M}$ decursin decreased p-STAT3, c-MYC, and CXCR7 levels in CXCR7-overexpressing cells. Histograms of the protein expression levels are presented in Fig. S5G. (D) Western blot analysis of CXCR7, p-STAT3, and c-Myc in SNU1041-CXCR7 and SNU1076-CXCR7 HNSCC cells treated with decursin or IL-6 for $48 \mathrm{~h}$. Histograms of the protein expression levels are presented in Fig. S5H. All blots are representative of 3 independent experiments. (E) Schematic illustration showing the mechanism by which decursin inhibits tumor progression via inhibition of the CXCR7/phospho-STAT3/c-MYC axis in HNSCC. HNSCC, head and neck squamous cell carcinoma; CXCR7, CXC chemokine receptor type 7; STAT3, signal transducer and activator of transcription 3.

Chemotherapy, in which cytostatic and cytotoxic agents target the cellular mechanisms involved in the control of cell growth and division, is frequently used in cancer treatment (30). However, chemotherapy alone does not achieve satisfactory therapeutic results, and resistance to cytotoxic chemotherapy is a major cause of mortality in patients. Therefore, the use of natural products is a recent and innovative strategy aimed at increasing the cytotoxic efficiency of anticancer drugs, limiting their toxic side effects and delaying the appearance of acquired chemoresistance (31). Decursin is derived from a natural product and has shown antitumor effects in several types of cancers, including gastric (22) and cervical cancer (32). However, the effect of this compound on HNSCC, characterized by high migration and invasion with poor clinical outcome, remains unclear. In the present study, decursin reduced cell growth, migration, and invasion in HNSCC by decreasing the expression of CXCR7. These results suggest that decursin could be an anticancer agent that exhibits antitumor activity by targeting CXCR7 in HNSCC.
Chemokine receptor 7 (CXCR7) promotes migration and invasion in HNSCC and is highly expressed in tumor cells in HNSCC patients (11). Moreover, several studies have indicated that CXCR7 regulates the PI3K/Akt, ERK, and MAPK signaling pathways in several cancer cell types $(33,34)$. CXCR7 plays an important role in cell division, induces differentiation-related cell cycle, and promotes proliferation (35). Consistent with these roles, decreased expression of CXCR7 has been correlated with the inhibition of cell cycle progression and marked changes in key proteins involved in cell cycle regulation (36). A recent study showed that chemokine pathways have become an important area of investigation for cancer therapy (37). An emerging chemokine target for cancer therapy is CXCL12, also known as the stromal cell-derived factor $1 \alpha(\mathrm{SDF}-1 \alpha)$, which binds its cognate receptor CXCR4 and initiates downstream signaling $(38,39)$. SDF-1 $\alpha$ also binds to CXCR7 and has been involved in tumor development and progression (40). In our study, CXCR7 overexpression alone increased cell growth via cell cycle progression and 
promoted cell motility, migration, and invasion, independently of SDF-1 $\alpha$, as previously reported by Kim et al (11). SDF-1 $\alpha$ treatment also increased cell motility and growth.

Signal transducer and activator of transcription 3 (STAT3) is constitutively activated in many cancers and plays a pivotal role in tumor growth and metastasis (41), including colon cancer (42), gastric cancer (43), cervical cancer (44), and hepatocellular carcinoma (45). STAT3 is an essential transcription factor that activates a cascade of survival and proliferation signaling programs in cells. Expression of phosphorylated (p)-STAT3 is an important factor related to tumor invasion and poor prognosis $(46,47)$. Furthermore, CXCR7-induced STAT3-mediated pathways may enhance tumor growth by regulating cell proliferative pathways; STAT3 signaling is associated with the upregulation of cyclin and c-MYC expression, contributing to accelerated cell cycle progression $(17,48)$. STAT3 is frequently overexpressed in tumor cells and the importance of STAT3 as a potential target for cancer therapy has been highlighted (49). STAT3 activity is regulated by posttranslational modifications, such as phosphorylation, acetylation, oxidation, and ubiquitination (50). Our results indicate that CXCR7 activates the STAT3/c-MYC signaling axis in HNSCC. Decursin treatment decreased the expression of CXCR7 and STAT3/c-MYC, suggesting that decursin may be a useful anticancer drug as it suppresses CXCR7/STAT3 signaling in HNSCC cells.

c-MYC is an important downstream effector of STAT3 signaling involved in cell growth and transformation (51). MYC is a transcription factor that responds to and integrates signals into broad changes in gene expression, supporting cell growth and proliferation (52). STAT3 and c-MYC are activated by interleukin (IL)-6, which regulates cell growth, differentiation, and cell survival $(53,54)$. The IL-6/STAT3 pathway is an attractive pharmacological target in oncology, and different approaches to target this pathway, such as direct targeting of STAT3 phosphorylation and activation or downregulation of STAT3 expression, are being pursued pre-clinically and clinically $(55,56)$. In the present study, we showed that STAT3 phosphorylation and c-MYC expression were increased by CXCR7, while decursin treatment decreased STAT3 phosphorylation and expression of c-MYC and CXCR7. Treatment with IL-6 increased STAT3 phosphorylation and c-MYC expression with no change in CXCR7. Co-treatment of decursin and IL-6 suppressed STAT3 phosphorylation and c-MYC expression less than treatment with decursin alone. Moreover, decursin inhibited cell growth, motility, and invasiveness. Collectively, these results indicate that decursin inhibits tumor progression via CXCR7/STAT3/c-MYC signaling in HNSCC.

To date, there is no established ideal experimental model for cancers including HNSCC because both in vitro and in vivo tumor models have advantages and disadvantages (57). In preclinical stage, most of cancer research is first investigated in in vitro models and later in in vivo systems (57). However, this study was performed using an in vitro model and thus have some limitations which should be considered and need to be overcome in future research. For example, cells growing in vitro do not exactly replicate their in vivo counterparts. Malignant tumors consist of both cancer cells and tumor microenvironment which makes the tumors a three-dimensional status with dynamic interaction between them $(57,58)$. Furthermore, the precise mechanism by which decursin downregulates expression of CXCR7 is not yet clear. Thus, we are undergoing further study to elucidate the molecular mechanism.

In summary, the present study showed the pro-tumorigenic effect of CXCR7 in HNSCC and revealed that CXCR7 induces p-STAT3 and downstream factors. Decursin suppressed tumor progression through the inhibition of p-STAT3 and c-MYC by decreasing CXCR7 expression. Thus, decursin may be a natural therapeutic drug useful in the treatment of HNSCC.

\section{Acknowledgements}

The abstract was presented at the 94th Annual Meeting of the American Association for Cancer Research Apr 10-May 21, 2021 in Philadelphia, IL and published as abstract no. 2412 in Cancer Res 81(13_Suppl), 2021: Abstract no. 2412.

\section{Funding}

This study was supported by grants from the National Research Foundation of Korea (NRF-2017R1D1A1B04034638, NRF-2017R1A5A2015385, 2017R1D1A1B04034379) and the Korea Health Technology R\&D Project through the Korea Health Industry Development Institute (KHIDI), funded by the Ministry of Health \& Welfare, Republic of Korea (HR20C0025).

\section{Availability of data and materials}

The data presented in this study are contained within the article and the Supplementary Materials.

\section{Authors' contributions}

Conceptualization of the study design was carried out by MJ, JMK, and HJL. Data curation was performed by MJ, YA, SK, NK and HJJ. Investigation and methodology were the responsibility of MJ, JBH, and GYS. Formal analysis of the results was carried out by MJ, JBH, HJJ, and JMK. Funding acquisition was obtained by JMK and HJL. Writing, review, and/or revision of the manuscript was carried out by MJ, YA, NK, GYS, JMK, and HJL. Project administration, resources and software were the responsibility of HJJ and JMK. Study supervision and data validation were the responsibility of JMK and HJL. All authors have read and agreed to the manuscript for publication.

\section{Ethics approval and consent to participate}

Not applicable.

\section{Patient consent for publication}

Not applicable.

\section{Competing interests}

The authors declare that they have no competing interests. 


\section{References}

1. Siegel RL, Miller KD and Jemal A: Cancer statistics, 2018. CA Cancer J Clin 68: 7-30, 2018

2. Solomon B, Young RJ and Rischin D: Head and neck squamous cell carcinoma: Genomics and emerging biomarkers for immunomodulatory cancer treatments. Semin Cancer Biol 52: 228-240, 2018

3. Goesswein D, Habtemichael N, Gerhold-Ay A, Mazur J, Wünsch D, Knauer SK, Künzel J, Matthias C, Strieth S and Stauber RH: Expressional analysis of disease-relevant signalling-pathways in primary tumours and metastasis of head and neck cancers. Sci Rep 8: 7326, 2018

4. Isaacsson Velho PH, Castro G Jr and Chung CH: Novel targeted agents in head and neck squamous cell carcinoma. Hemato Oncol Clin North Am 29: 993-1009, 2015.

5. Müller A, Homey B, Soto H, Ge N, Catron D, Buchanan ME, McClanahan T, Murphy E, Yuan W, Wagner SN, et al: Involvement of chemokine receptors in breast cancer metastasis. Nature 410: 50-56, 2001.

6. Liotta LA: An attractive force in metastasis. Nature 410: 24-25, 2001.

7. Zlotnik A: Chemokines in neoplastic progression. Semin Cancer Biol 14: 181-185, 2004.

8. Zlotnik A, Morales J and Hedrick JA: Recent advances in chemokines and chemokine receptors. Crit Rev Immunol 19: $1-47,1999$

9. Salazar N, Castellan M, Shirodkar SS and Lokeshwar BL: Chemokines and chemokine receptors as promoters of prostate cancer growth and progression. Crit Rev Eukaryot Gene Expr 23 : 77-91, 2013.

10. Pierce KL, Premont RT and Lefkowitz RJ: Seven-transmembrane receptors. Nat Rev Mol Cell Biol 3: 639-650, 2002.

11. Kim N, Ryu H, Kim S, Joo M, Jeon HJ, Lee MW, Song IC, Kim MN, Kim JM and Lee HJ: CXCR7 promotes migration and invasion in head and neck squamous cell carcinoma by upregulating TGF- $\beta 1 / \mathrm{Smad} 2 / 3$ signaling. Sci Rep 9: 18100 2019.

12. Liberman J, Sartelet H, Flahaut M, Mühlethaler-Mottet A, Coulon A, Nyalendo C, Vassal G, Joseph JM and Gross N: Involvement of the CXCR7/CXCR4/CXCL12 axis in the malignant progression of human neuroblastoma. PLoS One 7: e43665, 2012.

13. Wang J, Shiozawa Y, Wang J, Wang Y, Jung Y, Pienta KJ, Mehra R, Loberg R and Taichman RS: The role of CXCR7/RDC1 as a chemokine receptor for CXCL12/SDF-1 in prostate cancer. J Biol Chem 283: 4283-4294, 2008.

14. Liu TJ, Guo JL and Xu X: CXC chemokine-7 inhibits growth and migration of oral tongue squamous cell carcinoma cells, mediated by the epithelial-mesenchymal transition signaling pathway. Mol Med Rep 16: 6896-6903, 2017.

15. Iwakiri S, Mino N, Takahashi T, Sonobe M, Nagai S, Okubo K Wada H, Date H and Miyahara R: Higher expression of chemokine receptor CXCR7 is linked to early and metastatic recurrence in pathological stage I nonsmall cell lung cancer. Cancer 115 2580-2593, 2009.

16. Yates TJ, Knapp J, Gosalbez M, Lokeshwar SD, Gomez CS Benitez A, Ekwenna OO, Young EE, Manoharan M and Lokeshwar VB: C-X-C chemokine receptor 7: A functionally associated molecular marker for bladder cancer. Cancer 119 : $61-71,2013$

17. Wani N, Nasser MW, Ahirwar DK, Zhao H, Miao Z, Shilo K and Ganju RK: C-X-C motif chemokine 12/C-X-C chemokine receptor type 7 signaling regulates breast cancer growth and metastasis by modulating the tumor microenvironment. Breast Cancer Res 16: R54, 2014.

18. Yanagiya M, Dawood RI, Maishi N, Hida Y, Torii C, Annan DA, Kikuchi H, Yanagawa Matsuda A, Kitamura T, Ohiro Y, et al: Correlation between endothelial CXCR7 expression and clinicopathological factors in oral squamous cell carcinoma. Pathol Int 71: 383-391, 2021.

19. Schrevel M, Karim R, ter Haar NT, van der Burg SH, Trimbos JB, Fleuren GJ, Gorter A and Jordanova ES: CXCR7 expression is associated with disease-free and disease-specific survival in cervical cancer patients. Br J Cancer 106: 1520-1525, 2012.

20. Jiang C, Guo J, Wang Z, Xiao B, Lee HJ, Lee EO, Kim SH and $\mathrm{Lu}$ J: Decursin and decursinol angelate inhibit estrogen-stimulated and estrogen-independent growth and survival of breast cancer cells. Breast Cancer Res 9: R77, 2007.
21. Kim SH, Lee SW, Park HJ, Lee SH, Im WK, Kim YD, Kim KH, Park SJ, Hong S and Jeon SH: Anti-cancer activity of Angelica gigas by increasing immune response and stimulating natural killer and natural killer T cells. BMC Complement Altern Med 18: 218, 2018

22. Kim S, Kim JE, Kim N, Joo M, Lee MW, Jeon HJ, Ryu H, Song IC, Song GY and Lee HJ: Decursin inhibits tumor growth, migration, and invasion in gastric cancer by down-regulating CXCR7 expression. Am J Cancer Res 9: 2007-2018, 2019.

23. Lee S, Shin DS, Kim JS, Oh KB and Kang SS: Antibacterial coumarins from Angelica gigas roots. Arch Pharm Res 26: 449-452, 2003

24. Son SH, Kim MJ, Chung WY, Son JA, Kim YS, Kim YC, Kang SS, Lee SK and Park KK: Decursin and decursinol inhibit VEGF-induced angiogenesis by blocking the activation of extracellular signal-regulated kinase and c-Jun N-terminal kinase. Cancer Lett 280: 86-92, 2009.

25. Yim D, Singh RP, Agarwal C, Lee S, Chi H and Agarwal R: A novel anticancer agent, decursin, induces G1 arrest and apoptosis in human prostate carcinoma cells. Cancer Res 65: 1035-1044, 2005.

26. Lee JH, Kim MA, Park S, Cho SH, Yun E, O YS, Kim J, Goo JI, Yun MY, Choi Y, et al: Synthesis and evaluation of (+)-decursin derivatives as inhibitors of the Wnt $/ \beta$-catenin pathway. Bioorg Med Chem Lett 26: 3529-3532, 2016.

27. Kim WJ, Lee SJ, Choi YD and Moon SK: Decursin inhibits growth of human bladder and colon cancer cells via apoptosis, G1-phase cell cycle arrest and extracellular signal-regulated kinase activation. Int J Mol Med 25: 635-641, 2010.

28. Oh ST, Lee S, Hua C, Koo BS, Pak SC, Kim DI, Jeon S and Shin BA: Decursin induces apoptosis in glioblastoma cells, but not in glial cells via a mitochondria-related caspase pathway. Korean J Physiol Pharmacol 23: 29-35, 2019.

29. Tang Z, Li C, Kang B, Gao G, Li C and Zhang Z: GEPIA: A web server for cancer and normal gene expression profiling and interactive analyses. Nucleic Acids Res 45: W98-W102, 2017

30. Longley DB, Harkin DP and Johnston PG: 5-fluorouracil: Mechanisms of action and clinical strategies. Nat Rev Cancer 3: $330-338,2003$

31. de Oliveira Júnior RG, Christiane Adrielly AF, da Silva Almeida JR, Grougnet R, Thiéry V and Picot L: Sensitization of tumor cells to chemotherapy by natural products: A systematic review of preclinical data and molecular mechanisms. Fitoterapia 129: 383-400, 2018.

32. Yim NH, Lee JH, Cho WK, Yang MC, Kwak DH and Ma JY: Decursin and decursinol angelate from Angelica gigas Nakai induce apoptosis via induction of TRAIL expression on cervical cancer cells. Eur J Integr Med 3: e299-e307, 2011.

33. Liao YX, Zhou CH, Zeng H, Zuo DQ, Wang ZY, Yin F, Hua YQ and Cai ZD: The role of the CXCL12-CXCR4/CXCR7 axis in the progression and metastasis of bone sarcomas (Review). Int J Mol Med 32: 1239-1246, 2013.

34. Lin L, Han MM, Wang F, Xu LL, Yu HX and Yang PY: CXCR7 stimulates MAPK signaling to regulate hepatocellular carcinoma progression. Cell Death Dis 5: e1488, 2014.

35. Wang Y, Xu P, Qiu L, Zhang M, Huang Y and Zheng JC: CXCR7 participates in CXCL12-mediated cell cycle and proliferation regulation in mouse neural progenitor cells. Curr Mol Med 16: 738-746, 2016.

36. Salazar N, Muñoz D, Kallifatidis G, Singh RK, Jordà M and Lokeshwar BL: The chemokine receptor CXCR7 interacts with EGFR to promote breast cancer cell proliferation. Mol Cancer 13: 198, 2014

37. Duda DG, Kozin SV, Kirkpatrick ND, Xu L, Fukumura D and Jain RK: CXCL12 (SDF1 $\alpha$ )-CXCR4/CXCR7 pathway inhibition: An emerging sensitizer for anticancer therapies? Clin Cancer Res 17: 2074-2080, 2011.

38. Sun X, Cheng G, Hao M, Zheng J, Zhou X, Zhang J, Taichman RS, Pienta KJ and Wang J: CXCL12/CXCR4/CXCR7 chemokine axis and cancer progression. Cancer Metastasis Rev 29: 709-722, 2010

39. Kojima Y, Acar A,Eaton EN, Mellody KT, Scheel C, Ben-Porath I, Onder TT, Wang ZC and Richardson AL: Autocrine TGF-beta and stromal cell-derived factor-1 (SDF-1) signaling drives the evolution of tumor-promoting mammary stromal myofibroblasts. Proc Natl Acad Sci USA 107: 20009-20014, 2010.

40. Barbieri F, Bajetto A, Pattarozzi A, Gatti M, Würth R, Porcile C, Thellung S, Corsaro A, Villa V, Nizzari $M$ and Florio T: The Chemokine SDF1/CXCL12: A novel autocrine/paracrine factor involved in pituitary adenoma development. The Open Neuroendocrinol J 4: 64-76, 2011. 
41. Kamran MZ, Patil P and Gude RP: Role of STAT3 in cancer metastasis and translational advances. Biomed Res Int 2013: 421821, 2013

42. Corvinus FM, Orth C, Moriggl R, Tsareva SA, Wagner S Pfitzner EB, Baus D, Kaufmann R, Huber LA, Zatloukal K, et al: Persistent STAT3 activation in colon cancer is associated with enhanced cell proliferation and tumor growth. Neoplasia 7: $545-555,2005$.

43. Kim DY, Cha ST, Ahn DH, Kang HY, Kwon CI, Ko KH, Hwang SG, Park PW, Rim KS and Hong SP: STAT3 expression in gastric cancer indicates a poor prognosis. J Gastroenterol Hepatol 24: 646-651, 2009.

44. Morgan EL and Macdonald A: Autocrine STAT3 activation in HPV positive cervical cancer through a virus-driven Rac1-NFxB-IL-6 signalling axis. PLoS Pathog 15: e1007835, 2019.

45. Lee $\mathrm{C}$ and Cheung ST: STAT3: An emerging therapeutic target for hepatocellular carcinoma. Cancers (Basel) 11: 2019.

46. Dimri S, Sukanya and De A: Approaching non-canonical STAT3 signaling to redefine cancer therapeutic strategy. Integr Mol Med 4: 2017

47. Kusaba T, Nakayama T, Yamazumi K, Yakata Y, Yoshizaki A, Inoue K, Nagayasu T and Sekine I: Activation of STAT3 is a marker of poor prognosis in human colorectal cancer. Oncol Rep 15: 1445-1451, 2006.

48. Bartek J and Lukas J: Mammalian G1- and S-phase checkpoints in response to DNA damage. Curr Opin Cell Biol 13: 738-747, 2001.

49. Chai EZ, Shanmugam MK, Arfuso F, Dharmarajan A, Wang C, Kumar AP, Samy RP, Lim LH, Wang L, Goh BC, et al: Targeting transcription factor STAT3 for cancer prevention and therapy. Pharmacol Ther 162: 86-97, 2016.

50. Im JY, Kim BK, Lee KW, Chun SY, Kang MJ and Won M: DDIAS promotes STAT3 activation by preventing STAT3 recruitment to PTPRM in lung cancer cells. Oncogenesis 9: 1, 2020.
51. Tolomeo $\mathrm{M}$ and Cascio A: The multifaced role of STAT3 in cancer and its implication for anticancer therapy. Int $\mathrm{J}$ Mol Sci 22: 603, 2021.

52. Schaub FX, Dhankani V, Berger AC, Trivedi M, Richardson AB, Shaw R, Zhao W, Zhang X, Ventura A, Liu Y, et al: Pan-cancer alterations of the MYC oncogene and its proximal network across the cancer genome atlas. Cell Syst 6: 282-300.e282, 2018

53. Yu CY, Wang L, Khaletskiy A, Farrar WL, Larner A, Colburn NH and Li JJ: STAT3 activation is required for interleukin-6 induced transformation in tumor-promotion sensitive mouse skin epithelial cells. Oncogene 21: 3949-3960, 2002.

54. Wang SW and Sun YM: The IL-6/JAK/STAT3 pathway: Potential therapeutic strategies in treating colorectal cancer (Review). Int J Oncol 44: 1032-1040, 2014.

55. Aryappalli P, Al-Qubaisi SS, Attoub S, George JA, Arafat K, Ramadi KB, Mohamed YA, Al-Dhaheri MM, Al-Sbiei A, Fernandez-Cabezudo MJ and Al-Ramadi BK: The IL-6/STAT3 signaling pathway is an early target of manuka honey-induced suppression of human breast cancer cells. Front Oncol 7: 167, 2017.

56. Zou S, Tong Q, Liu B, Huang W, Tian Y and Fu X: Targeting STAT3 in cancer immunotherapy. Mol Cancer 19: 145, 2020.

57. Arantes-Rodrigues R, Colaço A, Pinto-Leite R and Oliveira PA: In vitro and in vivo experimental models as tools to investigate the efficacy of antineoplastic drugs on urinary bladder cancer. Anticancer Res 33: 1273-1296, 2013.

58. Varley CL and Southgate J: Organotypic and 3D reconstructed cultures of the human bladder and urinary tract. Methods Mol Biol 695: 197-211, 2011.

This work is licensed under a Creative Commons Attribution-NonCommercial-NoDerivatives 4.0 International (CC BY-NC-ND 4.0) License. 